\title{
La legislación eclesiástica, el cabildo indígena del Hospital del Cuzco y la relación entre Murúa y Guaman Poma
}

\author{
Eclessiastical Law, the Indigenous Council of the Hospital of Cuzco, \\ and links between Murúa and Guaman Poma \\ José Cárdenas Bunsen \\ Vanderbilt University, Tennessee, Estados Unidos \\ Contacto: Jose.cardenas-bunsen@vanderbilt.edu \\ https://orcid.org/0000-0002-5809-5749
}

\section{Resumen}

Este ensayo explora el tratamiento del corpus conciliar en las obras de Martín de Murúa y Guaman Poma de Ayala. Sostiene que Murúa incorporó cercanamente los decretos conciliares para fundar su autoridad de cronista y presentar su trabajo como si fuera una extensión de la obra del concilio que le permitiera ofrecer consejos a las autoridades civiles y eclesiásticas sobre materia indiana. Análogamente, Guaman Poma se apoyó en los decretos de los sínodos limenses en diversos capítulos de su Nueva corónica y sobre esta base sustentó sus propuestas principales de reforma eclesiástica. Sin embargo, la principal diferencia de su aproximación, en contraste con Murúa, reside en que Guaman Poma empleó esos mismos decretos para demoler la imagen que el fraile mercedario había elaborado de sí mismo, mostrar la ineficacia de los consejos que extendía a las autoridades eclesiásticas, desautorizar sus libros e insinuar las penas que merecía Murúa por desobedecer e instrumentalizar la jurisdicción eclesiástica.

Palabras claves: Martín de Murúa; Felipe Guaman Poma de Ayala; Sínodo limense; Decreto conciliar; Reforma eclesiástica; Cabildo; (Auto) representación; Informantes.

\begin{abstract}
This essay examines the use of ecclesiastical council records in the works of Martin de Murua and Guaman Poma de Ayala. It argues that Murua used the Council decrees to support his authority as chronicler and to present his work as an extension of the Council's. This would have allowed him to offer advice about Indian matters to civil and ecclesiastical authorities. In a similar direction, Guaman Poma used the decrees of the Lima Council meetings in several chapters of his chronicle to sustain his main proposals for ecclesiastical reform. The main difference between his use of these documents and that of Murua's is that Guaman Poma used them to demolish the friar's image, show the inefficacy of his potential advice to Church officials, unauthorize his books and suggest
\end{abstract}


the punishments Murua deserved because he desobeyed and manipulated ecclesiastical jurisdiction.

Keywords: Martín de Murúa; Felipe Guaman Poma de Ayala; Lima Synods; Council decree; Cabildo (council); Church reform; (Self) representation; Informants

Recibido: 24.08.19 Aceptado: 17.10.19

Felipe Guaman Poma y Martín de Murúa mantuvieron un estrecho contacto intelectual. El autor andino ilustró la primera versión de la Historia de Murúa y posteriormente lo criticó severamente en su Nueva corónica. Murúa, por su parte, trabajó con informaciones de los caciques de las parroquias del Cuzco y de Guaman Poma, de quien conservó un escudo cuya leyenda aludía al linaje de su abuelo Guaman Chaua (Murúa, 2008, p. 307r). Este ensayo se aproxima al vínculo entre estos dos cronistas desde el ángulo de la legislación eclesiástica y de la actuación del cabildo indígena del Hospital del Cuzco. Sostiene que las fuentes, los informantes y los temas en la obra de Murúa se explican por la asociación y/o sanción de estos elementos con los distintos ordenamientos jurídico-eclesiásticos emanados de la autoridad episcopal y virreinal. Sobre estas bases, Murúa articula los intereses de los caciques cuzqueños y se construye una imagen de buen cura, conocedor de la lengua, historia y costumbres nativas, ello fruto de la obra de la orden mercedaria a través de los lineamientos del Tercer Concilio de Lima y las ordenanzas de Francisco de Toledo. Guaman Poma análogamente autorizó su Nueva corónica y algunas de sus propuestas principales de reforma en la misma legislación eclesiástica. La principal diferencia de su aproximación consiste en que Guaman Poma empleó ese corpus para demoler la imagen que Murúa había elaborado de sí mismo, inclinarse por una política favorable al clero secular y proponer la ordenación sacerdotal de los indios. Además, al reclamar para su padre la misma posición que la de los caciques informantes de Murúa, el cronista andino compartió su programa temático y artístico.

Para sustentar estas hipótesis rastreo las alusiones y citas de la legislación eclesiástica en la obra de ambos cronistas y las complemento con el seguimiento documental del cabildo indígena del Hospital de los Naturales del 
Cuzco, cuyas actividades iluminan aspectos de la temática visual y argumental de ambos cronistas y el posible interés que pudo tener la élite nativa en el libro de Murúa. Por haber comenzado a escribir antes de Guaman Poma, empiezo con el análisis de la obra del fraile mercedario.

\section{Murúa frente a la legislación eclesiástica}

La concepción de las dos versiones de la crónica de Murúa está estrechamente vinculada a la política eclesiástica de fines del siglo XVI. Los intereses de la Orden de la Merced y su interacción con las decisiones del Obispado del Cuzco y del Arzobispado de Lima explican la inclusión de ciertos episodios históricos y la elección de las fuentes históricas citadas con el fin potencial de proyectar los hechos históricos con un estatus favorable para la orden ante los ojos del lector. El perfil mismo de Martín de Murúa cubría el vacío de "frailes graves y letrados" que la orden buscaba llenar desde 1570. Con este fin se había solicitado el apoyo del rey para el paso a Indias de estos, arguyendo ser orden antigua en el Perú, leal al rey en los levantamientos de los conquistadores y capaz de ocuparse de doctrinas en los pueblos andinos (Barriga, 1933, I, pp. 30, 124-128)1. La titularidad de estas doctrinas se vio amenazada por las políticas del Obispado del Cuzco. Desde 1560, el cabildo cuzqueño decidió retirar las doctrinas que estaban a cargo de las órdenes religiosas. Los mercedarios apelaron la decisión e impulsaron una probanza para asentar su eficiente labor en la conversión de los naturales, que contó con el apoyo de Polo de Ondegardo (Barriga, 1933, II, pp. 239-240). A pesar de estos esfuerzos, en 1585 el cabildo retiró los curatos a las órdenes y convocó a oposiciones a clérigos seculares ${ }^{2}$. No obstante, el Tercer Concilio de Lima, el sínodo con mayor autoridad, no proponía en sus decretos una política contraria a los curatos regidos por las órdenes religiosas.

Este corpus eclesiástico anterior a 1590, la fecha más temprana consignada en la obra de Murúa, se articula complejamente en las versiones de su crónica. En primer lugar, los argumentos de los mercedarios a favor de sus servicios cristalizan en el capítulo inicial de la crónica sobre la participación de la orden en la conquista del Perú (Murúa, 2004, 8r/v). Así, se proyectaban a la serie 
de capítulos referentes a la actividad de la orden en el gobierno espiritual, donde Murúa repitió la tesis oficial mercedaria de ser una de las más antiguas órdenes y patrocinadora de misiones en las provincias del Perú, Santa Cruz, Tucumán, Paraguay y Chile (Murúa, 2008, 324r-330r). En segundo lugar, las decisiones del Tercer Concilio, no contrarias a las órdenes religiosas y aprobadas con la participación de los provinciales mercedarios ${ }^{3}$, ocupan un rol principal en la obra de Murúa. El Tercer Concilio había mandado explícitamente conocer sus decretos a todos los curas y había confirmado las decisiones de los sínodos metropolitanos anteriores de 1552 y 1567 (Vargas Ugarte, 1952, I, pp. 322-323). El fraile hizo constar ante su lector su familiaridad con esta legislación canónica mediante la autorización de sus opiniones con sus decretos. En un capítulo dedicado a ofrecer consejos a los corregidores en materia religiosa, Murúa recomienda proceder con extremo sigilo en la identificación de las creencias nativas, evitar escandalizar a los naturales y erradicar sus prácticas religiosas con discreción, para lo cual anota: "no es éste remedio nuebo que en el concilio provincial de Lima hecho en el año de mil y quinientos y sesenta y siete y en el congregado el año de mil y quinientos y ochenta y tres confirmado por la santidad de Sixto V se mandó se hiziese lo que en este capítulo refiero" (2008, 300v; Vargas Ugarte, 1952, 3, pp. 32-37). El cronista adopta reiteradamente una posición similar a la del concilio, tratando de fortalecer la validez de sus argumentos y la importancia de su narración, para lo que indica que sus conocimientos históricos y su experiencia como doctrinero lo llevan a coincidir con $-\mathrm{y}$ aun complementar- los textos refrendados por la autoridad episcopal.

La impronta del corpus textual de los concilios limenses en los escritos de Murúa informa los criterios de la escritura histórica y constituye un pilar central sobre el que este autor asienta su figura de cronista. Pudo encontrar una aprobación a su interés histórico por los usos y costumbres nativos en el proemio al Confesionario trilingüe, donde el concilio había establecido la necesidad de que los curas doctrineros se informasen sobre los patrones religiosos nativos, mandándoles que "apunten y hagan memoria dello y lo adviertan al obispo o a su visitador de palabra o por escrito" (Tercer Concilio, 1985 [1584], p. 201; 
Vargas Ugarte, 1952, I, pp. 257 sub 122). Los temas cubiertos por la crónica de Murúa y sus comentarios muestran que el autor acata esta y otras decisiones de los concilios, dejándolas entrever en numerosos pasajes y entretejiéndolas en su narración histórica. Se explican así las interrupciones del mercedario en el hilo de su narración para insertar comentarios sustentados en los mandatos del concilio. Por ejemplo, la narración de los amores de los hermanos Sayre Tupa Inga y Cusi Huarcay se detiene para acoger una consideración sobre que

[...] los curas que doctrinamos a estos yndios lo deuemos adbertir en que no caminen a parte ninguna con sus hermanas ni parientas ni los padres con las hijas y mucho menos las madres con sus hijos por algunas cosas que yo en muchos años como cura dellos e sabido. $(2008,219 \mathrm{v})$

En esta digresión, Murúa observa el mandato del concilio para combatir el incesto en primer grado de consanguinidad, según se estipulaba en numerosos decretos y en la colección de sermones sobre los impedimentos del matrimonio (Vargas Ugarte, 1952, I, pp. 245-246; Tercer Concilio, 1985 [1584], pp. 527-528). En otras ocasiones, el mercedario estalla en expresiones de celo pastoral que recogen el afán conciliar por regular la vida eclesiástica. Los concilios limenses pretendían erradicar la corrupción del clero, como lo demuestra la inclusión en los papeles originales de una opinión solicitada por los prelados de Lima a los obispos mexicanos sobre el rol de los sínodos en la vida ejemplar del clero (Sínodos, 1582-1604, 196r). Sobre esta base, Murúa pide descartar intereses superfluos y entregarse a la conversión de los indios:

[...] todos los que en este reino andamos en la combersión de las almas de estos miserables, devemos asello con un celo santo de procurar la honra de Dios y anunciar su santo nombre en estas naciones, dejados otros vanos e inútiles intereses, que hacen perder el premio digno a los trabaxos que entre ellos se padecen. $(2008,179 \mathrm{v})$

Así, la legislación conciliar actúa como una de las fuentes programáticas más consistentes que este cronista explícita o tácitamente observa y que le ofrece incluso la plataforma para emprender su propia pesquisa histórica. En conformidad con este corpus, Murúa levanta su figura de conocedor de las antigüedades de los indios. En 1590 y luego en 1596, trató de refrendar este conocimiento con los 
nombres de los caciques cuzqueños que habían informado sus investigaciones y con la carta de recomendación de estos señores para la publicación de su libro, donde declaraban que él mismo se había informado de los indios más ancianos y de ellos mismos para escribir su historia (2008, 307v). Sorpresivamente, al reordenar las páginas de sus libros, Murúa decidió silenciar las identidades de sus informantes y esconder su carta, pegando contra folios nuevos las páginas donde figuraban sus nombres y su recomendación (Ossio, 2014, pp. 16-18, 28; Cummins, 2014, pp. 36-40). No obstante, al suscribir la carta en 1596, la intervención de estas autoridades cuzqueñas acusa el interés que las élites indígenas podían tener en una obra como la de Murúa. Las actividades de don Luis Chalco permiten entrever las motivaciones de su apoyo. Su posición social dependía enteramente de la legislación eclesiástica anterior al Tercer Concilio, también emanada del virrey Toledo.

\section{La política eclesiástica toledana y el Hospital de los Naturales: el caso de don Luis Chalco}

Las identidades de los informantes nativos de Murúa han sido reveladas recientemente (Cummins y Ossio, 2013, pp. 155-156). Debajo de la primera acuarela de la obra del mercedario se leen los nombres de don Pedro Purqui, cacique principal de los indios cañaris de la parroquia de Santa Ana; don Martín Quispe Topa, cacique principal de la parroquia de San Cristóbal; don Mango Topa, cacique principal de la parroquia de Santiago; don Juan Quispe Cussi Inga, cacique de la parroquia de San Blas; y don Luis Chalco Yupanqui, gobernador mayor del Cuzco y de todas sus parroquias (Murúa, 2004, 1v; Cummins y Ossio, 2013, pp. 155-156). El rango y la adscripción de estos informantes vinculan esta obra con el mundo de las parroquias del Cuzco, en las que Francisco de Toledo mandó integrar a toda la población nativa de la ciudad (Aparicio, 1963, pp. 120121). Sus posiciones, entonces, habían quedado establecidas en las ordenanzas toledanas que resultaron de una visita general detalladamente instruida por Toledo y realizada por un equipo. Sus instrucciones mandaban averiguar la identidad de los titulares de los cacicazgos de cada pueblo, los patrones de su 
sucesión, la jurisdicción de la que gozaban y los tributos que pagaban en tiempos de los incas (Ordenanzas..., 1604, 68v-74v; Mumford, 2012, pp. 85-89). Toledo previó también que se redujera el número de jerarcas indígenas, quitándoles los servicios personales que los naturales prestaban a los "mandones y principales" y manteniendo únicamente los privilegios de "los caçiques principales del repartimiento y segundas personas y los caciques de guarangas y pachacas" (Ordenanzas..., 1604, 88v). Para la década de 1590, los caciques principales conformaron un grupo que mantuvo - o incluso adquirieron — sus privilegios tras la reforma toledana. Los caciques representaban a cuatro de las siete parroquias del Cuzco que habían sido confirmadas en las ordenanzas de Toledo y operaron entre 1590 y 1616 (Levillier, 1925, p. 111).

La presencia de don Mango Topa entre los informantes de Murúa se explica por la relación de la parroquia de Santiago con el convento de la Merced, donde Murúa escribió la primera versión de su crónica. El ayllu Choco, adscrito a esta parroquia, proveía yanaconas y sacristanes al convento y, en 1645, los Topa se mantenían como caciques de dicho ayllu (Lista de los indios..., 1645, 1r/v). El caso de don Luis Chalco confirma el vínculo de los informantes de Murúa con las parroquias. Las ordenanzas toledanas estipulaban que cada parroquia eligiera anualmente un alcalde de entre los naturales, que ejecutase las órdenes del corregidor, asistiese en las causas judiciales de los naturales y ordenase las fiestas de la parroquia (Levillier, 1925, p. 114). Esta elección implicaba la congregación de un cabildo con potestad para realizar la elección de estos funcionarios. De los registros de tales comicios solo se conserva el libro de cabildo y ayuntamiento de la iglesia de Nuestra Señora de los Remedios, que servía como parroquia del Hospital de los Naturales del Cuzco. Su asamblea de caciques y yanaconas tenía la misión de renovar a los alcaldes, regidores y obrero mayor de la parroquia los primeros días del mes de febrero y tomar residencia al cabildo saliente (Libro de cabildo..., 1602-1627, 10r-14v).

En la elección del 2 de febrero de 1606, don Luis Chalco actuó como traductor del cabildo secular del Cuzco que asistía a las elecciones del cabildo del Hospital para confirmarlas. Para oficializar la elección, 
[...] fueron llamados los electos y por lengua e interpretación de don Luis Chalco se recibió dellos juramento en forma de derecho que usarán bien e fielmente sus oficios y guardarán las hordenansas del señor birrey don Francisco de Toledo y no consentirán idolatrías y borracheras. (Libro de cabildo..., 1602-1627, 43r)

La actuación de don Luis Chalco como traductor entre el cabildo de la ciudad del Cuzco y el cabildo de la parroquia lo coloca en la élite cultural nativa que se ocupaba de estas labores de mediación (Adorno, 1994, pp. 378387; De la Puente, 2014, pp. 145-150). A su figura se le pueden atribuir las características de los intérpretes proyectadas en las instrucciones de Toledo que los caracteriza como personas de confianza, imparciales y conocedoras de las lenguas (Ordenanzas..., 1604, 64v). Durante los años en que Guaman Poma y Murúa escriben, el contexto de las labores y actividades del directorio parroquial que Luis Chalco ayuda a instituir abre una ventana para comprender la posición de los caciques en las parroquias y la selección de parte de los temas que Murúa, primero, y Guaman Poma, después, historian e ilustran. El cabildo del Hospital muestra el pleno funcionamiento de las ordenanzas toledanas y desempeña un rol preponderante en la vida ritual de la comunidad parroquial. Tenía entre sus electores a sus caciques principales, quienes gozaban de voz para proponer a los fiscales de las doctrinas y a otros oficiales (Libro de cabildo..., 1602-1627, 2r). Este ayuntamiento, además, favorecía el rango social del cacique principal en la vida de la parroquia; el cabildo del 2 de abril de 1585 le confirmó sus honores y preeminencias "como gobernador del pueblo", permitiéndole llevar cada año el estandarte de la parroquia en la procesión del Corpus Christi rodeado por los miembros del cabildo que sostenían el palio y por los mandones de cien indios que portaban los maceros (Libro de cabildo..., 1602-1627, 4r/v). Como las ordenanzas toledanas contemplaban la inclusión de danzas indígenas en las procesiones (Levillier, 1925, p. 113), el cabildo del Hospital año tras año planificaba, con la participación del cura beneficiado, el desfile y alarde festivo para la procesión de la Virgen de los Remedios, la semana santa y el Corpus Christi. Además, establecía la cantidad de palmas y flores que aportaría cada ayllu; nombraba a los cargadores de las andas; programaba en años sucesivos el baile de los aymaraes, de los guancas, 
de los yungas, de los collas y del inga; aumentaba a conveniencia la cantidad de "invenciones y taquies"; mandaba adornar la plaza de la iglesia con "altares en sus cuatro esquinas" decorados con pendones, paños y guadamecíes; y regulaba la asistencia de ingas y yanaconas con vestuarios y plumerías de distintas zonas de los Andes (Libro de cabildo..., 1602-1627, 4r, 9r, 11v, 13r, 15r, 16v). La intensa vida ritual de las parroquias en la que sus informantes tomaban parte se registra en clave histórica en la crónica de Murúa y explica la atención que el cronista concedía a estos aspectos de la cultura indígena y que han llevado a considerarlo “el gran chambelán de los incas” (Porras, 1948, p. 809; Ossio, 2000-2002, p. 55).

Narrativamente, Murúa registró la práctica de las procesiones y fiestas, al igual que sus antecedentes, en la época incaica. Ilustró también la variedad de las vestimentas mediante los retratos de incas, coyas y capitanes; la identificación verbal de cada ornamento dibujado; el calendario ritual; las plumerías de los danzantes; la "fiesta del ynga"; la "procesión general de los indios antiguos" y las celebraciones matrimoniales son temas centrales de su programa artístico. Estas acuarelas, entre las cuales sabemos hoy que Guaman Poma preparó la número 99, anticiparon los dibujos de la Nueva corónica (Murúa, 2004, 9v, 10r, 17v, 81v-84r, 97v, 98r, 126r; Guaman Poma, 2001 [1615], pp. 86, 260, 320, 329, 862) ${ }^{4}$.

La coincidencia entre las actividades del cabildo y el programa temático de los cronistas señala la interdependencia entre su versión histórica y el contexto social de sus informantes. ¿Qué partes del libro de Murúa les podía interesar a estos caciques? Además de mostrar los antecedentes históricos de las prácticas culturales de sus parroquias, potencialmente les pudo interesar la proyección histórica de sus jerarquías cuyos orígenes y funciones aparecían en la narración de Murúa. El cronista los presenta como gente principal estrechamente asociada a los incas y definida como señores de indios "que verdaderamente quiere decir señor que tiene a cargo la gente [cacique]", detallando las preeminencias, ordenamiento y honores que recibían del inca en perpetuidad (Murúa, 2004, 52v, 57 r/v; 2008, 250r/v). De la narración histórica de Murúa se desprende que los caciques estaban en los comienzos de una vida política de los Andes antes de la aparición de los incas: 
[...] antiguamente no hubo señor general de toda la tierra, sino que en cada provincia y en cada parentela y generación se gobernaban como behetría por el más principal curaca o cacique de ella y tenían sus pueblezuelos y casa sin orden, apartada una parentela o aillo de la otra. (2004, 8v; 2008, 16r)

Según Murúa, con el surgimiento de los incas, la historia de los caciques se integró a su gobierno y fue elogiada porque "una sola ley había entre esta gente que era no traspasar el derecho de naturaleza" (2004, 54r). Por las implicaciones políticas de su historia, Murúa consignó el nombre de sus informantes detrás de una alegoría del origen de la política. Anticipando el recurso de Guaman Poma de utilizar la imagen como refuerzo de su argumentación histórica (Adorno, 2000 [1986], pp. 83-89), Murúa escogió como primera ilustración de su crónica una imagen de un inca armado de una honda en el momento inmediatamente anterior a la caza de un animal (figura 1, Murúa, 2004, 1v).

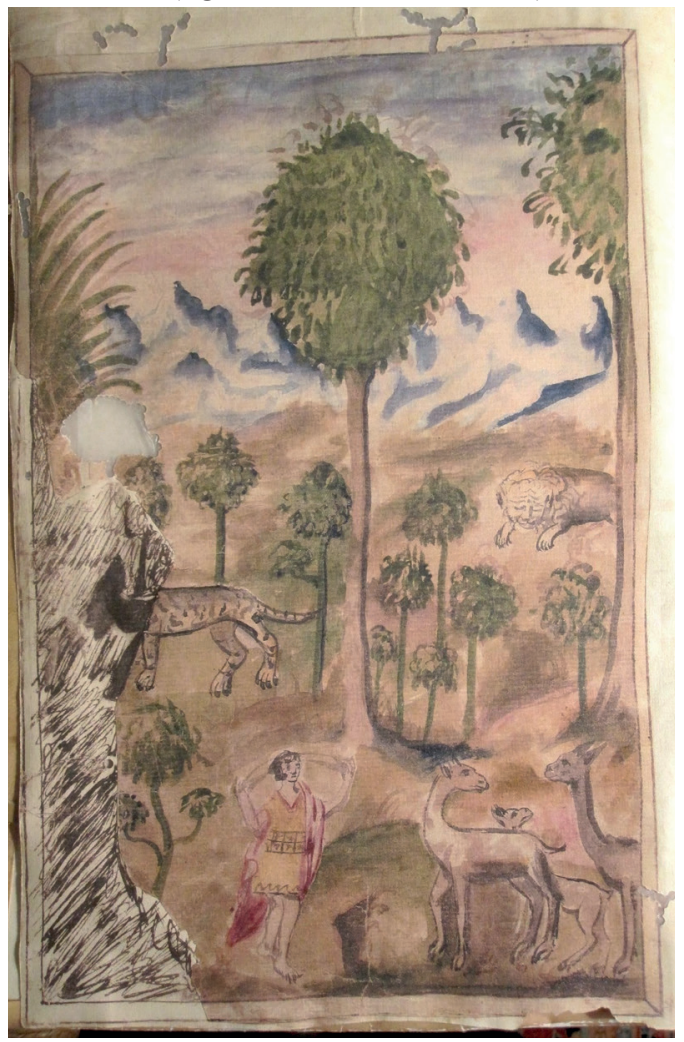

Figura 1. Martín de Murúa, Historia del origen de los incas (1598).

Reproducido con permiso de Juan Ossio. 
Esta imagen cumple una importante función argumental que toca la cuestión de la legitimidad del dominio indio que Murúa defiende en distintos lugares de su crónica. Para estos efectos, la escena de la cacería resulta decisiva. Esta acuarela traslada al ámbito andino la alegoría aristotélica del origen del dominio y del nacimiento de la guerra explicados precisamente con el ejemplo de la cacería (Aristóteles, 1998, 1256b). Los tratadistas de Indias interpretaban este pasaje como una prueba de que la posesión de las cosas exteriores es justa y defendida por el derecho natural para todos los hombres del mundo (Las Casas, 1997, pp. 1236-1237). Murúa era lector de Aristóteles y, en especial, de la Política, texto que cita explícitamente para hablar de la tiranía de Manco Cápac (2008, 20v). Las implicaciones argumentales de esta acuarela inciden en la legitimidad del señorío indígena y en la asociación de los inicios políticos de los Andes a la ley natural, cuya observación continuada le permitirá al autor afirmar que las leyes incas acusaban "indicios de mucha policía que guardaron y de su prudencia y sauer" $(2008,270 v)$. Estos fundamentos, a su vez, justifican que Francisco de Toledo recogiera numerosas leyes incas en sus ordenanzas y Felipe II las mandara respetar $(2004,125 \mathrm{v} ; 2008,271 \mathrm{r})$. La supervivencia de la autoridad de los caciques representa, así, el primero y el último eslabón de esa cadena sostenida en la ley natural y mantenida por los incas y por las ordenanzas de Toledo. Su participación como informantes de la crónica y su relación con Murúa se explican por el funcionamiento de la política eclesiástica que los ha vinculado institucional y personalmente a las parroquias, y cuyos intereses se articulan en clave histórica en ciertos temas y argumentos de la crónica de Murúa. Para este, la comunicación con los caciques del Cuzco y los indios viejos acentuaba su conocimiento de la lengua de los indios y enlazaba una vez más con las líneas más conspicuas de la política eclesiástica general.

\section{El quechua y las fuentes de Murúa}

Murúa se apresura a mostrar su pericia en quechua en casi todas las páginas de su crónica; así, transcribe las frases que supuestamente habrían pronunciado ciertos incas o señores indios, elabora retratos verbales en quechua para complementar 
los retratos de los incas y explica sistemáticamente las etimologías quechuas de los nombres de las ciudades indias que describe en su historia (2004, 9v, 10r, 13r; 2008, 210v, 357v, 360r).

Al expresar su conocimiento lingüístico, Murúa se mostraba obediente de las disposiciones eclesiásticas sobre las habilidades de los curas en lenguas indígenas. Numerosos decretos repetidos en los tres concilios limenses exigían probar la solvencia requerida en quechua para acceder al curato, merecer la congrua (renta mínima de un oficio eclesiástico o civil) y oír confesiones sin intérpretes (Vargas Ugarte, 1952, I, pp. 123, 226, 235). En este punto, no existía oposición frente a las políticas del Obispado del Cuzco, que también exigía el conocimiento de las lenguas nativas y había instituido un examen de lengua para los aspirantes a los curatos (Libro primero..., s. f., 74r). El Tercer Concilio decretó que se usaran exclusivamente los textos que habían traducido al quechua y al aimara e inclusive publicó una gramática y un diccionario quechuas que complementaban tales textos (Vargas Ugarte, 1952, I, p. 323; Cárdenas, 2014a, pp. 88-95). El Concilio acuñó las directrices sobre ortología (arte de pronunciar correctamente) quechua que siguen los fragmentos quechuas de Murúa (Cerrón Palomino en Ossio, 2004, p. 65). Esta adopción de convenciones ortográficas es una marca indeleble que liga el trabajo del mercedario con la labor del Concilio.

Hay una dimensión menos visible de la legislación eclesiástica en la obra de Murúa que explica la inclusión de las posturas antitéticas de Polo de Ondegardo y de Bartolomé de Las Casas en su crónica. Murúa organizó todos los capítulos sobre religión indígena siguiendo al pie de la letra a Polo de Ondegardo y añadiéndole las acuarelas de Guaman Poma. En los escritos de Polo convergían los intereses de la orden mercedaria y la autoridad del Tercer Concilio, lo que lo convirtió en el autor más apto para seguirlo en materia de religión indígena. Polo había sido autor póstumo publicado con la autoridad del Tercer Concilio; en vida había instituido las cuatro primeras parroquias del Cuzco y había favorecido a su orden en el pleito que sostuvo contra el cabildo del Cuzco (Barriga, 1933, II, pp. 239-240; Porras, 1948, pp. 594; Álvarez-Calderón 2007, p. 167; Tercer Concilio, 1985 [1584], pp. 265-283). 
Martín de Murúa conoció también los impresos lascasianos de 1552. Resumiendo las conclusiones de la Brevísima relación de la destrucción de las Indias, sostuvo que las guerras de conquista eran injustas y realizadas sin recta intención solo para alimentar una codicia insaciable. También aludió al sumario de la disputa con Juan Ginés de Sepúlveda, mencionando que Las Casas había negado la condición bárbara de los indios $(2008,167 v)$. En el estadio final de su manuscrito, Murúa —o su censor- canceló algunas líneas de raigambre lascasiana (Adorno, 2004, pp. 52-55). A pesar de estas supresiones, la Historia general del Pirú conservó las tesis fundamentales de que los despojos a los indios eran injustos:

[...] les habían quitado [sus haciendas] los españoles con desorden y poco temor de Dios, como si los ingas e indios no fueran señores de sus haciendas, sino que todo estuviera perdido el dominio y aplicado a quien primero pudiese tomarlo por fuerza. (Murúa, 2008, 192v)

Este reconocimiento del dominio de los indios y su derecho a restitución era un asunto elevado a decreto episcopal por las decisiones de distintos concilios limenses. El Segundo Concilio había decretado

[...] que se ha de restituir a los indios lo que se les ha tomado haciéndoles agravios, y que las restituciones inciertas se harán bien dándose a los ospitales o iglesias de indios lo que se les debe y desto deven avissar los escrivanos quando hacen testimonios. (En Vargas Ugarte, 1952, I, p. 239)

Este decreto aplicaba a nivel metropolitano la decisión de un sínodo local presidido por Jerónimo de Loayza en 1560 y aprobado por todos los superiores de las órdenes religiosas; en este se adoptaron las disposiciones del confesionario de Bartolomé de Las Casas para administrar la confesión a los encomenderos (Lopetegui, 1945, p. 581; Lohmann, 1966, p. 57). Los prelados oficializaban su coincidencia con los postulados legales y teológicos que sostenían la argumentación de Las Casas, pues estos procedían de los principios más fuertes del derecho canónico y no podían ser abolidos, ni siquiera por una legislación como la que llegó a propiciar el virrey Toledo, que tuvo que admitir la restitución de las posesiones a los indios y mandó su estricta supervisión en las instrucciones de la visita (Ordenanzas..., 1604, 79r; Cárdenas, 2014b, pp. 795-797). A través de 
esta cadena de mediaciones, Murúa, al reafirmar en su crónica el dominio legítimo que asistía a los naturales, no corría un gran riesgo intelectual, pues esa premisa se amparaba en la aprobación de las tesis defendidas por de Las Casas ante los sínodos limenses, cuyo corpus textual se revela como el hilo conductor por el cual Murúa dialoga con las grandes líneas del pensamiento político y teológico sobre las Indias. Apurando el análisis, la impugnación de Murúa contra la legalidad de las guerras de conquista sustentada en citas y paráfrasis de Bartolomé de Las Casas, su desaprobación de los despojos ilegítimos contra los indios, sus invectivas contra la codicia insaciable y su condena de la falta de autoridad de Pizarro para ejecutar a Atahualpa sirven para presentar entre líneas los elementos que desplazan la justificación de la conquista a la arena estrictamente religiosa y refuerzan los pasajes donde la providencia aparece moviendo los destinos del Perú y la labor de los religiosos en la conversión de los naturales $(2008,126 \mathrm{v}-127 \mathrm{v}$, 51r, 134v-137r, 145r, 150v).

En conclusión, el vínculo de Murúa con la legislación eclesiástica desvela sus estrategias para construir su imagen de autor ante sus lectores y aclara parte de sus motivaciones para interesarse en la historia indígena. Escribirla complementa su perfil de buen doctrinero y de quechuista conocedor de las costumbres e historia indígenas. Todas estas cualidades venían aprobadas por los concilios en distintas decisiones. Guaman Poma ilustró la primera versión de la crónica de Murúa con 99 acuarelas en las que añadió numerosas informaciones (Adorno y Boserup, 2008, p. 43). En su segunda versión, el fraile descartó la mayoría de estos dibujos, pero conservó un escudo con las armas de los antiguos señores del Tahuantinsuyu que había ilustrado Guaman Poma para adornar la carta al rey de los curacas del Cuzco. Allí, Murúa cedió a Guaman Poma un lugar para adelantar un argumento axial de su Nueva corónica: la antigüedad y legitimidad de su estirpe paterna frente a los otros señores del Tahuantinsuyu (2008, 307r). Este dibujo es la prueba visual de su mutua relación intelectual y artística de la que forma parte central la cultura impresa y manuscrita que comparten. A este respecto, la misma legislación eclesiástica fue también lectura de cabecera del cronista indio y arma efectiva contra Martín de Murúa. 


\section{Guaman Poma de Ayala frente a la legislación eclesiástica}

La Nueva corónica y buen gobierno se apoya en un solvente conocimiento de la legislación eclesiástica. La relación más estrecha con este corpus aparece en la sección que Guaman Poma dedica a los padres de las doctrinas: "como los dichos padres de las dotrinas no quieren guardar ni ciguir lo que manda el santo concilio y hordenansas y provisiones reales de su magestad" (pp. 565-566) ${ }^{5}$. Esta referencia del cronista alude no solamente a los decretos sinodales, sino también a las ordenanzas del virrey Toledo. Sobre estas bases, el cronista andino consigue sustentar una profunda crítica del clero y mantenerse dentro de la ortodoxia más estricta (Charles, 2011, pp. 210-217). Guaman Poma realiza entonces una operación análoga a la de Martín de Murúa, no solo al autorizar sus propuestas mediante la alusión a las disposiciones conciliares, sino también al adoptar las opiniones de Bartolomé de Las Casas e historiar las mismas instituciones que aparecían mencionadas en el apéndice al Confesionario para curas de indios (Adorno, 2000 [1986], pp. 23-27). Como Murúa, Guaman Poma también se guía por el texto de Polo de Ondegardo, refundiéndolo en ocasiones, siguiendo su orden expositivo, elaborando siempre la información e insertando numerosas observaciones ausentes en Polo (pp. 276, 237-261; Tercer Concilio, 1985 [1584], pp. 274, 270-273).

Aparte de estas estrategias similares en la composición de su obra, hay grandes diferencias que separan su proyecto de las historias de Murúa. La principal consiste en que Guaman Poma empleó la misma legislación para pulverizar la imagen autorial que tan cuidadosamente había construido el mercedario en las dos versiones de su crónica. Guaman Poma mencionó cinco veces al fraile Murúa en la Nueva corónica para denunciar los abusos del mercedario contra los indios (Ossio, 2004, pp. 50-51). Toda la crítica del autor indígena se basaba en la observación de los decretos de los concilios y en la representación sistemática que hizo de Murúa. El cronista andino atribuyó acciones al fraile e invirtió el sentido de los decretos conciliares. Murúa aparece, por ejemplo, maltratando a los indios tanto que los obliga a huir del pueblo de Aimaraes (p. 521). El autor también 
descarga su artillería en el retrato que consigna del fraile como comendador del pueblo de Yanaca, ya que lo acusa de haber destruido a los indios con la imposición de trabajos, servicios personales, rapiña de sus bienes, levantamiento de falsos testimonios, castigos arbitrarios y obstrucción de la justicia (pp. 662663). Este retrato violaba la provisión del Concilio que estipulaba que los curas de indios debían procurar la conversión de los naturales sobre todo con el ejemplo de vida y que, para tal efecto, no debían pedirles nada material, bajo pena de restituirlo por el doble de su valor (Vargas Ugarte, 1952, I, p. 241). Guaman Poma logra representar dramáticamente los alcances de su crítica contra el "mercenario Morúa" mediante la atribución del siguiente sermón en quechua:

Churi, allilla oyari. Cay aymarata carcuspa, uarcuspa, rupachispa camta comenderotauan corregidortauan pacha auachiscaymanta, conpichiscaymanta; solterasconata uacillaypi puscachiscaymanta quexauanqui. ¿Atipasac niuanquicho? ¿Pi obispo, pi rrey? Mana diospa rantinta ymana cacho. Ropa chichiscayquim manzeba nispa hichesero nispa. Alli ricciuay. Caypi uanosac. Coracata uanochispa lluccisac. Asotillauan rimachiscayqui, aymara pleytista, yndio. (p. 625) [Hijo, óyeme bien. Te quejarás con el encomendero y con el corregidor, porque he mandado a tejer ropa y porque he mandado a tejer ropa fina botando, colgando y quemando a este aimara; y porque he mandado hilar a las solteras en mi casa. ¿Me dirás "lo venceré"? ¿Quién es el obispo; quién, el rey? Nada le harán al mensajero de Dios. Haré que te quemen diciendo que estás amancebado y que eres un hechicero. Conóceme bien. Aquí moriré. Después de matar al curaca, saldré. Con el azote te haré hablar, aimara pleitista, indio. (p. 625; mi traducción)]

El conocimiento de la lengua indígena que demandaba el Tercer Concilio se encaminaba a la acción pastoral de los curas y también al cuidado del buen vivir de los indios, ya que "conforme al apóstol primero es lo corporal y animal, que lo espiritual e interior" (Vargas Ugarte, 1952, I, p. 373). Al contrastar este sermón con los decretos pertinentes a la lengua, el conocimiento del quechua por parte de Murúa no puede pervertir más la intención de tales mandatos eclesiásticos al presentar a un fraile amenazante y listo a calumniar a su congregación nativa. La figura de buen doctrinero que Murúa había procurado para sí al insertar consejos pastorales en su crónica queda hecha pedazos en la representación de Guaman Poma. Esta 
descarnada crítica contra el mercedario apunta, en última instancia, a la ruptura total de la jurisdicción eclesiástica por parte del mismo. El sermón de Murúa lo anticipa con la exclamación “¿Quién es el obispo; quién, el rey?” que muestra la elación de Murúa renuente a reconocer a ninguna autoridad por encima de sí mismo.

El cura doctrinero aparece sistemáticamente retratado abusando de su oficio, infringiendo las restricciones de su puesto e instrumentalizándolo para salvarse en caso de que la justicia eclesiástica lo castigase. Según Guaman Poma, Murúa "quitaua mujeres casadas y a las hijas y hermanas de los indios" (p. 662). Este acto equivalía a usurpar la autoridad reservada al obispo en la ruptura de los matrimonios indígenas (Vargas Ugarte, 1952, I, p. 249) ${ }^{6}$. El fraile se arrogaba entonces la autoridad de visitador sin haber sido nombrado en ese rol por ninguna autoridad: "Con su disciplina castigaua y se hacía visitador" (p. 662). Esta falta de respeto contra la jurisdicción eclesiástica era una acusación grave, pues mostraba a un Murúa que viciaba la posición que la Iglesia proveía para inspeccionar el buen funcionamiento de las doctrinas $y$, con el miedo que creaba entre los indios, bloqueaba una estipulación muy concreta que disponía que el visitador eclesiástico procurara "que tengan entera libertad los indios de declarar sus quexas o agravios si les pareciere havérselos con su cura" (Vargas Ugarte, 1952, I, p. 362). Para combatir tales abusos, el Concilio castigaba el mal proceder del visitador, su disimulo perverso de los vicios eclesiásticos e incumplimiento de estas normas con la excomunión (Vargas Ugarte, 1952, I, p. 362). Con su crítica, Guaman Poma realza retóricamente la modestia y buena intención de su lección de buen gobierno al refrenarse de fulminar una excomunión contra Murúa. Su silencio se debe, sin duda, a su intención de reforzar su condición de consejero de reyes y prelados sin usurpar lo mínimo del oficio y atribuciones de estos superiores, aunque sí se sirve del caso negativo de Murúa para asentar su consejo en política eclesiástica: "No es bueno que sea flayre doctrinante cino questén en sus conuentos. Que los clérigos son de la horden de los apóstoles dotrinantes" (p. 663). Aquí Guaman Poma se alinea exactamente con las políticas del Obispado del Cuzco que mandaban retirar a los frailes de las doctrinas para poner a los clérigos, una medida que Murúa había tratado de contrarrestar en su 
crónica adoptando los lineamientos del Tercer Concilio Limense (cfr. nota 2). Guaman Poma no suaviza su demolición de Murúa y reporta que este decía que "aunque le echasen de la doctrina, que auía de ir al convento a comer y dormir" (p. 662). Esta observación de Guaman Poma es el ápice de su crítica a Murúa, ya que lo presenta como un cura dispuesto a abusar del aparato eclesiástico de manera tal que, si recibiera alguna condena del obispo, siempre podría utilizar su condición de fraile regular para refugiarse en la orden mercedaria, recibir la protección del provincial y utilizar en su beneficio la armazón jurisdiccional de la Iglesia. La crítica de Guaman Poma no podía ser más elocuente. Murúa se convierte en el arquetipo del mal sacerdote y la causa para la reforma.

A pesar de esta fortísima crítica, el cronista andino reconoce que Murúa es un "gran letrado" (p. 521). La racionalidad de este elogio, por un lado, acentúa el alcance de su diatriba al subrayar la plena comprensión de sus acciones y la imposibilidad de que se ampare en la ignorancia. Por otro lado, salva parte del trabajo histórico del mercedario. Guaman Poma había participado en el proceso de escritura de Murúa y conocía la naturaleza de su información. El autor indígena había elaborado numerosas acuarelas para el fraile. En varias de estas, había agregado líneas identificatorias de objetos y personajes y había defendido la antigüedad y señorío de su familia en sus páginas (Murúa, 2008, 307r; Guaman Poma, 2001 [1615], p. 75). Posiblemente estas consideraciones lo llevaron a no condenar del todo a Murúa a pesar de criticar severamente el carácter incompleto de su libro ("ni comensó ni acabó"), por no referirse con precisión al origen y final del linaje de los incas (p. 1090). La asociación de las vertientes informativas de Murúa con los caciques de las parroquias del Cuzco puede contarse también entre las razones de Guaman Poma para colaborar artísticamente con Murúa y llamarlo "gran letrado". Como don Luis Chalco, Guaman Poma había sido traductor, testigo y asistente de Gabriel Solano de Figueroa en varias actuaciones jurídicas (Porras, 1948, pp. 72-73; Pereyra, 1997, p. 268). A mayores coincidencias, el cronista reclamaba para su padre una posición social idéntica a la de los caciques principales de las parroquias cuzqueñas que habían sido informantes de Murúa. Don Martín Guaman Malque de Ayala era "cacique principal” y "sirbió a dios 
treynta años a los pobres del Hospital de la ciudad del Cuzco y de la ciudad de Guamanga" (p. 15). Así, la similitud de su programa histórico y artístico de usos y costumbres nativos con el de Murúa procedían de su acceso, según su propio perfil biográfico, al mismo fondo cultural a través de su padre, don Martín de Ayala, quien estuvo sometido a las mismas ceremonias, al mismo calendario religioso y a un régimen social semejante al de los caciques principales como atestigua el libro del cabildo del Hospital del Cuzco (pp. 14-17).

Como se puede apreciar, la relación del material que usa Guaman Poma con el corpus de legislación eclesiástica no se agota en su crítica al clero, encarnada paradigmáticamente en su demolición de Murúa, pues sustenta el puesto de su padre en el Cuzco y en Huamanga. La mayor función de esta legislación en la Nueva corónica consiste en fundar las propuestas más importantes de reforma religiosa. Los concilios de Lima habían provisto numerosas decisiones para regular la administración de los sacramentos a los indios. El Primer Concilio había enumerado los pasos a seguir para administrar el bautismo entre los conversos nativos (Vargas Ugarte, 1952, I, pp. 10-11). También había descrito minuciosamente las dispensas, la ratificación de las uniones naturales extra ecclesiam y los matrimonios mixtos (Vargas Ugarte, 1952, I, pp. 15-18). El Segundo Concilio proveyó las reglas para la administración de la confirmación, la confesión y la extremaunción (Vargas Ugarte, 1952, I, pp. 181-185, 193). El Tercer Concilio perfeccionó estos decretos al crear el corpus trilingüe para la administración de los sacramentos. Faltaba, sin embargo, la concesión del orden sacerdotal a los indios. Guaman Poma es consciente de ese vacío y decide abrir su libro con la petición al Papa de la dispensa de ese sacramento entre los indios:

[...] nos ahumillamos a buestra sancta yglecia católica a que dé la licencia del sancto sacramento sazerdotal pues que ya vuestra sanctidad a concedido en nosotros todas las demás y para su sancto servicio estamos en las manos de vuestra sanctidad. Y juntamente con ella le cirbo con esta poquita de obrecilla yntitulado Primer corónica y bue[n] [goui] ern[o] deste rreyno que es servicio de Dios y de vuestra Santidad. (p. 4)

Es muy significativo que la solicitud del sacerdocio se asociara con la escritura y presentación de su crónica. De haberla leído, el Papa podría apreciar 
en sus páginas los argumentos necesarios para esa reforma que eliminaría del clero a intermediarios corruptos como Murúa y que se presentaba como el paso que aún no habían dado los concilios, pero que era necesario para consolidar la décima edad del mundo de creciente cristiandad (p. 925). Con su dominio de la legislación eclesiástica, Guaman Poma había logrado crear el espacio para sustentar esa reforma y con su lección de buen gobierno llegó a demostrar que no existía impedimento para negar tal concesión.

Frente a la legislación eclesiástica, Guaman Poma y Murúa se comportan de manera análoga. Ambos cronistas conocieron, manejaron e incorporaron sus textos para autorizar sus opiniones y sustentar el alcance de sus afirmaciones. Si Murúa quiso sentar sobre esa base su imagen de cura ejemplar y observante de los decretos del Concilio, Guaman Poma apeló a la autoridad de los mismos textos para abatirlo intelectualmente y mostrarlo como un fraile abusivo e irrespetuoso de la jurisdicción eclesiástica. Más allá de este manejo creativo de las leyes de la Iglesia que hace Guaman Poma, se superpone en el texto su lectura y propuesta de que la autoridad eclesiástica dé el paso necesario que faltaba en los concilios: admitir a los indios al orden sacerdotal. Esta petición es la primera formulación de esta naturaleza en la historia andina. En una época en que Iglesia y corona no estaban separadas, la postura de Guaman Poma representó una de las propuestas más fuertes de reforma política y social.

\section{Agradecimientos}

Agradezco a la directora del Archivo Arzobispal del Cuzco, Graciela Romero Quispe, y al archivero Humberto Mora Almirón por su asistencia en la consulta de los documentos del Cuzco.

\section{Notas}

1 Probablemente Murúa llegó al Perú en 1577, es decir, durante la década en que su orden estaba buscando frailes letrados (Condarco Morales, 1997, p. 277; Ossio, 2008, p. 78, 93 n 11).

2 "El dicho señor deán y cabildo dixeron que mandauan y mandaron que se den y declaren por vacas todas las doctrinas y curatos y encomiendas en que al presente están por curas 
frailes regulares y [...] mandaron que se pongan edictos públicos de las dichas vacantes y cada una dellas para que los clérigos seculares que se quisieren oponer lo puedan hazer libremente dentro del término de los dichos edictos [Cuzco, 11 de enero de 1585] (Libro primero..., s. f., 82r).

3 Nicolás de Ovalle, provincial de la orden mercedaria, asistió y firmó las actas del Tercer Concilio de Lima (Vargas Ugarte, 1952, I, p. 321).

4 La regulación de la vida ritual de la parroquia y la institución anual del cabildo son los aspectos mejor documentados en el libro del cabildo. Este órgano canalizaba también otros asuntos de la vida de la comunidad parroquial, como la concesión de permisos a los naturales para ausentarse de las misas semanales, el control de las tasas de maíz, la recepción de las peticiones de las cofradías, la ejecución de ciertas peticiones del cura sobre la fábrica de la parroquia y el cuidado de las limosnas para las sepulturas de los indios (Libro de cabildo..., 1602-1627, 2v, 3v, 4v, 5r).

5 Todas las citas textuales provienen de la edición digital, con paginación corregida, que se puede consultar aquí: http://www.kb.dk/permalink/2006/poma/info/en/frontpage.htm (Guaman Poma, 2001 [1615]). De aquí en adelante solo citaremos la página cuando refiramos esta obra.

6 El mandato del Segundo Concilio es muy claro a este respecto: "que ningún sacerdote sea osado a apartar yndios ya casados por cualquiera causa y ocasión que ellos aleguen, mas remitan al diocesano qualesquier causas y negocios de divorcio para que él por su persona las determine" (Vargas Ugarte, 1952, I, p. 249).

\section{Referencias bibliográficas}

Adorno, R. (1994). The indigenous ethnographer: The "indio ladino" as historian and cultural mediation. En S. B. Schwartz (Ed.), Implicit Understandings. Observing, reporting and reflecting on the encounters between Europeans and other peoples in the Early Modern Era (pp. 378-402). Cambridge: Cambridge University Press.

Adorno, R. (2000 [1986]). Guaman Poma. Writing and Resistance in Colonial Peru. Austin: University of Texas Press.

Adorno, R. (2004). La censura de la Historia general del Perú (1611-1613) de fray Martín de Murúa. En I. Arellano y F. del Pino (Eds.), Lecturas y ediciones de crónicas de Indias. Una propuesta interdisciplinaria (pp. 37-76). Madrid: Iberoamericana Vervuert.

Adorno, R. y Boserup, I. (2008). The Making of Murúa's Historia general del Pirú. En T. B. F. Cummins y B. Anderson, The Getty Murúa. Essays on the Making of Martín de Murúa's Historia General del Pirú, J. Paul 
Getty Museum Ms. Ludwig XIII 16 (pp. 7-75). Los Angeles: The Getty Research Institute.

Álvarez Calderón, A. (2007). La crónica de fray Martín de Murúa: mentiras y legados de un mercedario vasco en los Andes. Revista Andina, 45, 159-182. Recuperado de http://revistaandinacbc.com/wp-content/ uploads/2016/ra45/ra-45-2007-07.pdf

Aparicio Vega, M. J. (1963). Documentos sobre el virrey Toledo. Revista del Archivo Histórico del Cuzco, 1, 119-144.

Aristóteles. (1998). Politics. Cambridge: Harvard University Press.

Barriga, V. M. (Ed.). (1933). Los mercedarios en el Perú en el siglo XVI. Documentos inéditos del Archivo General de Indias. Roma: Tipografía "Madre di Dio".

Cárdenas Bunsen, J. (2014a). Circuitos del conocimiento: el Arte de la lengua índica de Valera y su inclusión en las polémicas sobre el Sacro Monte de Granada. Lexis, 38, 1, 71-116.

Cárdenas Bunsen, J. A. (2014b). Consent, Voluntary Jurisdiction and Native Political Agency in Bartolomé de Las Casas' Final Writings. Bulletin of Spanish Studies, 91(6), 793-817. doi: 10.1080/14753820.2014.888887

Charles, J. (2011). Felipe Guamán Poma de Ayala en los foros de la justicia eclesiástica. En A. de Zaballa Beascoechea (Ed.), Los indios, el derecho canónico y la justicia eclesiástica en la América virreinal (pp. 203-222). Madrid: Vervuert.

Condarco Morales, R. (1997). Protohistoria andina. Propedéutica. Oruro: Universidad Técnica de Oruro.

Cummins, T. B. F. (2014). Dibujado de mi mano: Martín de Murúa as Artist. En T. B. F. Cummins, E. A. Engel, B. Anderson y J. M. Ossio (Eds.), Manuscript Cultures of Colonial Mexico and Peru. New Questions and Approaches (pp. 35-64). Los Angeles: The Getty Research Institute.

Cummins, T. B. F. y Ossio, J. (2013). "Muchas veces dudé Real Mag. aceptar esta dicha ympressa": la tarea de hacer la famosa historia de los reyes incas de fray Martín de Murúa. En J. C. Garavaglia, J. Poloni-Simard y G. Riviere (Eds.), Au Miroir de l'anthropologie historique. Mélanges 
offerts à Nathan Wachtel (pp. 151-170). Rennes: Presses Universitaires de Rennes.

De la Puente Luna, J. C. (2014). The many tongues of the King: Indigenous interpreters and the making of the Spanish Empire. Colonial Latin American Review, 23(2), 143-170. doi: 10.1080/10609164.2014.917545

Guaman Poma de Ayala, F. (2001 [1615]). El sitio de Guaman Poma. Nueva corónica y buen gobierno. Copenhague: Biblioteca Real. Recuperado de http://www.kb.dk/permalink/2006/poma/info/en/frontpage.htm

Las Casas, B. de. (1997). Tratados. Ciudad de México: Fondo de Cultura Económica.

Levillier, R. (1925). Gobernantes del Perú. Cartas y Papeles, tomo VIII: Ordenanzas del virrey Toledo. Madrid: Imprenta de Juan Pueyo.

Libro de cabildo y ayuntamiento del Hospital de los naturales del Cuzco. (16021627). Cuzco: Archivo Arzobispal del Cuzco. Época colonial. Parroquia de San Pedro. Cabildo y Ayuntamiento.

Libro primero del cabildo eclesiástico del Cuzco. (s/f). Cuzco: Archivo Arzobispal del Cuzco. Época colonial. Catedral. Libros de Cabildo.

Lista de los indios tributarios y viejos que hay en la parroquia de Santiago de la Ciudad del Cuzco (1645). Biblioteca Nacional del Perú. Manuscrito B854.

Lohmann Villena, G. (1966). La restitución por conquistadores y encomenderos: un aspecto de la incidencia lascasiana en el Perú. En Estudios lascasianos (pp. 21-89). Sevilla: Escuela de Estudios Hispanoamericanos.

Lopetegui, B. (1945). Apuros en los confesionarios. Missionalia Hispánica, 2, 571-584.

Mumford, J. R. (2012). Vertical Empire. The General Resettlement of Indians in the Colonial Andes. Durham: Duke University Press.

Murúa, F. M. de. (2004). Historia del origen y genealogía real de los reyes ingas del Pirú, edición facsimilar. Madrid: Testimonio Compañía Editorial.

Murúa, F. M. de. (2008). Historia general del Pirú. Facsimile of J. Paul Getty Museum Ms. Ludwig XIII 16. Los Angeles: Getty Research Institute. 
Ordenanzas del virrey Francisco de Toledo (1604). Lima: Biblioteca Nacional del Perú. Manuscrito B511 C.

Ossio, J. (2000-2002). Guamán Poma y Murúa ante la tradición oral andina. Íconos, 4, 44-57.

Ossio, J. (2004). Introducción. En F. M. de Murúa. Códice Murúa: Historia y genealogía de los reyes incas del Perú del padre mercedario fray Martín de Murúa (pp. 7-72). Madrid: Testimonio Compañía Editorial.

Ossio, J. (2008). Murúa's Two Manuscripts: A Comparison. En T. B. F. Cummins y B. Anderson (Eds.), The Getty Murúa. Essays on the Making of Martin de Murúa's Historia General del Pirú, J. Paul Getty Museum Ms. Ludwig XIII 16 (pp. 77-94). Los Angeles: The Getty Research Institute.

Ossio, J. (2014). New Assessment of the Hidden Texts in the Galvin Manuscript of Fray Martín de Murúa. En T. B. F. Cummins, E. A. Engel, B. Anderson y J. M. Ossio (Eds.), Manuscript Cultures of Colonial Mexico and Peru. New Questions and Approaches (pp. 11-34). Los Angeles: The Getty Research Institute.

Pereyra Chávez, N. (1997). Un documento sobre Guamán Poma de Ayala existente en el Archivo Departamental de Ayacucho. Histórica, 21(2), 261-270. Recuperado de http://revistas.pucp.edu.pe/index.php/historica/ article/view/8504

Porras Barrenechea, R. (1948). El cronista indio Felipe Huamán Poma de Ayala. Lima: Lumen.

Sinodos de Santo Toribio de Mogrovejo. (1582-1604). Lima: Archivo del Cabildo Metropolitano de Lima.

Tercer Concilio Provincial de Lima. (1985 [1584]). Doctrina Christiana y catecismo para instrucción de los indios. Edición facsimilar. Madrid: Consejo Superior de Investigaciones Científicas.

Vargas Ugarte, R., S. J. (1952). Concilios limenses (1551-1772). Lima: Arzobispado de Lima. 